\title{
ESTADO Y FAMILIA EN LOS PAISES DEL ESTE
}

\author{
M. Jesús Izquierdo \\ (Universidad Autónoma de Barcelona)
}

\section{INTRODUCCION}

Durante los últimos años, el papel del Estado y los límites del gasto público son temas que han saltado al foro. Si en la crisis económica de los años treinta el Estado jugó un papel crucial en el relanzamiento de la economía al incrementarse el gasto y la inversión pública, en la crisis económica que arrastramos desde inicios de los años setenta, por sus especiales características de inflación y paro, países como EE.UU. y Gran Bretaña responsabilizan en buena medida de la situación a la dimensión y distribución interna del presupuesto estatal. En nuestro propio país, sectores tal vez no numerosos pero sí ruidosos defienden la enseña de la liberalización del mercado.

Bajo el debate liberalización-intervencionismo se esconde una tensión constante entre la defensa de intereses particulares a corto plazo y la reproducción del propio sistema. Una reducción del gasto público en servicios colectivos, sean sanitarios, educativos, subsidios al desempleo, etc., aligera el peso de la empresa privada. Pero el sistema como un todo requiere, para su supervivencia, mantener las condiciones de producción y reproducción de la fuerza de trabajo, y hacerse cargo de aquella fuerza de trabajo que no encuentre un lugar en el mercado.

$\mathrm{El}$ drama que se representa en el escenario occidental tiene tres actores: la empresa, el Estado y el individuo. La empresa busca la maximización del beneficio reduciendo costes y aumentando precios; el Estado intenta hacer 
compatibles los intereses del empresario individual con los de la clase empresarial; y el individuo se siente y es sujeto pasivo del drama, puesto que la utilización de su capacidad productiva y reproductiva queda determinada por los que toman realmente las decisiones en este espacio escénico: la empresa y el Estado.

La alternativa operante con que nos topamos es la que viene denominándose «socialismo real», en donde los actores ya no son tres sino dos: el Estado y el individuo. La sociedad civil, como mediadora entre el uno y el otro, no está presente. El modo en que se planifica la economía, en que se definen las necesidades sociales, en que se emplean las energías productivas, son un conjunto de decisiones en las que no interviene el individuo, sea por la vía directa o por la vía representativa, ya que falta el eslabón intermedio entre el individuo y el Estado.

Así es como en los países del Este nos encontramos con un Estado prepotente que quiere ser, y no siempre lo consigue, PADRE, PATRón y MADRE. Padre en tanto que es el proveedor de los medios materiales para vivir, patrón en tanto que es el principal empleador de la fuerza de trabajo, y madre en la medida en que intenta sustituir a ésta por medio de los mal llamados servicios colectivos, mal llamados porque ni están gestionados por la colectividad ni la colectrvidad ha definido previamente las necesidades que dan origen a los mismos.

Como hemos visto, una diferencia entre Occidente y el Este es el número de sujetos significativos, en el primer caso la empresa, el Estado y el individuo; en el segundo, el Estado y el individuo. Un punto de coinci. dencia substantivo es el acento puesto en la industrialización. La esfera de la producción de bienes de cambio, en el marco de la división técnica del trabajo, cobra una gran importancia. Al mismo tiempo que la producción de bienes de uso, la no especialización por tareas, queda relegada e incluso obstaculizada por entenderse como un residuo de anteriores modos de producción y un factor de freno para el desarrollo de ambos modelos de sociedad, en lugar de considerarla como un elemento integrado armónicamente en el conjunto de actividades encaminadas a la satisfacción de las necesidades materiales humanas.

El proceso de industrialización, que en los países occidentales tiene como sujetos activos a la empresa y el Estado, y en los países del Este al Estado, conduce a una progresiva salarización del trabajo y a una violenta alienación del individuo, entendida como separación de sí mismo, de las demás personas y de las cosas. El trabajador asalariado queda separado de sí mismo en la medida en que se ve obligado a alquilar su fuerza de trabajo para producir una mercancía sobre la que no tiene control, en términos de cantidad, calidad y modo de organizar su producción. A cambio de su 
fuerza de trabajo, no obtiene directamente los medios para satisfacer sus necesidades materiales, sino la representación de esos medios, el dinero. Por tanto, el trabajador queda separado de sí mismo, ya que no controla ni disfruta lo que él mismo hace. En cuanto a la separación entre las personas, dado que la división del trabajo, por una parte conduce a la dependencia recíproca de todos los miembros de la sociedad, pero esta dependencia queda mediatizada por el dinero, cuando producimos algo, no sabemos quién lo va a consumir. $Y$ se produce la separación entre las personas y las cosas, ya que en muchos casos no llegamos a ver acabado el bien en cuya producción hemos intervenido. ${ }^{1}$

No obstante, la división técnica del trabajo no lleva aparejada necesariamente la alienación, y es claramente eficiente para proporcionar bienes y servicios en cantidad y variedad inimaginable con una división profesional del trabajo. La industrialización conduce a la alienación cuando la persona asalariada actúa sin incidir sobre el uso que da a su fuerza de trabajo, y lo que no es menos importante, mientras no puede decidir el tiempo que personal y socialmente se va a dedicar en una sociedad a la producción de bienes de cambio.

Los bienes de uso, a los que en los países industrializados se otorga una importancia marginal, dan una respuesta positiva a los problemas de alienación que se acaban de apuntar. Productor y consumidor están relacionados, se sabe y se decide sobre lo que se produce, cómo se produce y para qué.

La división de la producción en dos esferas: la de la mercancía y la de los bienes de uso coincide en buena medida con una división previa, la división sexual del trabajo. Hoy, en cualquier país industrializado (sea en Occidente $o$ en el Este) es la mujer la que realiza la mayor parte del trabajo no asalariado, y lo realiza precisamente en el marco de la institución familiar. En los últimos decenios (en la URSS más precozmente) los países industrializados han tendido, mediante la intervención del Estado, a vaciar parcialmente las funciones del ama de casa, salarizando tareas como el cuidado de niños, enfermos y viejos, por lo que incide significativamente en el ámbito familiar, y así refuerza la tendencia de todo proceso de industrialización a vaciar de contenido la familia, que deja de ser unidad de producción, para dotarla de contenidos nuevos al convertirse en unidad de consumo de mercancías.

En las líneas que siguen a continuación veremos la forma en que ha

1. Este enfoque de la alienación está tratado con más amplitud en F. Borrás y M. J. Izquierdo, La nova solidaritat: lluita sindical $i$ alienació, «Nous Horitzons», núm. $68,1980$. 
tenido lugar este proceso en la URSS y en los países que se encuentran bajo su esfera de influencia; y añadiremos, a estos aspectos de la relación entre el Estado y la familia que acabamos de apuntar, el tema de la utilización de la familia por parte de los intereses estatales como medio de transmisión de ideología.

Nos interesan sobre todo, para comprender el modelo de industrialización que se desarrolla en los países de socialismo real, tres aspectos que consideramos fundamentales:

a) La incorporación masiva de la mujer a la división técnica del trabajo.

b) El intento del Estado de asumir parte de las tareas atribuidas originalmente a la familia, en lo que se refiere a la producción y reproducción de la fuerza de trabajo.

c) La utilización de la familia por parte del Estado como elemento socializador coherente con un modelo de sociedad no participativa.

\section{LA FAMILIA SOVIÉTICA TRAS LA REVOLUCIÓN}

Con el triunfo de la revolución soviética se abrió un período de debate en torno a la familia que se centraba en los motivos que aconsejaban, de una parte, su desaparición y, de otra, su continuidad. Por un lado, preva lecía la idea de que la familia era portadora de valores propios de un orden social —el capitalista- que la revolución pretendía superar. Además, las tareas de construcción de la base material del socialismo requerían la fuerza de trabajo de la mujer. Sin embargo, la desaparición de la familia dejaría sin cubrir servicios como: la crianza y socialización de niños y niñas, la preparación de alimentos, el cuidado de enfermos, y un largo etcétera, a menos que se hiciera cargo de ello otra institución, el Estado.

Así se fueron desarrollando dos tendencias claramente diferenciadas en el seno del Partido Bolchevique. El ala «izquierdista» era partidaria de la desaparición de la familia y defendía la libertad sexual, mientras que el ala «derechista» consideraba que la familia ni desaparecería ni debería desaparecer. ${ }^{2} \mathrm{La}$ idea dominante era que no se podía mantener una posición abiertamente negativa respecto a la institución familiar, ya que la

2. H. Kent Giger, «The fate of the family in Soviet Russia: 1917-1944», en Bell y Vogel, $A$ modern introduction to the family, Londres, Routledge and Kegan, 1960. Tratan también el tema: Alejandra Kollontai, La mujer en el desarrollo social, Barcelona, Guadarrama, 1976. Y Santiesteban, La mujer y el socialismo: ¿camaradas o comparsas?, «El Viejo Topo», núm. 10, 1980. 
transición no había hecho más que empezar y continuaban existiendo relaciones económico-sociales capitalistas y precapitalistas. El nuevo Estado continuaba siendo débil y los servicios colectivos estaban por crear; mientras todos estos problemas no quedaran resueltos no se podía abolir la familia. Se entendía, en definitiva, que el partido debía jugar un papel activo de coordinación entre la familia y la organización de la vida soviética en general.

La incorporación de la mujer a la producción social ocasionó cambios importantes en la vida cotidiana. Facilitar, aún más, impulsar la incorporación de la mujer a la producción de bienes de cambio implicaba que el Estado asumiera las responsabilidades que hasta ese momento eran propias de la mujer. Es decir, se planteaba un Estado que, adelantándose incluso a la concepción occidental del Welfare State, asumiera todavía más funciones, tantas, que le fuera aplicable el término de Estado Maternal. ${ }^{3}$ Para Lenin, sólo el socialismo y la desaparición de la pequeña economía familiar salvaría a las mujeres del trabajo doméstico, que por otra parte se consideraba antieconómico, es más, la liberación de la mujer se consideraba una precondición para el desarrollo económico.

El período que siguió a la revolución de Octubre fue de una actividad sexual sin restricciones. Se deshicieron muchas familias y muchos hijos fueron concebidos fuera del matrimonio. No obstante, si bien la legislación de 1917-1918 debilitaba los lazos conyugales, en modo alguno abolía la familia como institución social.

La legislación soviética sobre la familia mantenía los siguientes principios:

1. Monogamia.

2. Reconocimiento del matrimonio de hecho y del civil como formas únicas de matrimonio formal. ${ }^{4}$

3. Máxima simplificación de los trámites de divorcio: el mutuo acuerdo entre los cónyuges era suficiente.

4. Separación de bienes.

5. La mujer dejaba de estar obligada a seguir al marido en caso de cambio de residencia.

3. Este término lo tomo de Agnes Heller, que lo utiliza en el artículo La famiglia nel «welfare state», "Crítica Marxista», número noviembre-diciembre 1978.

4. El reconocimiento del matrimonio de hecho pudiera deberse a que la mayoría de matrimonios religiosos no estuvieran dispuestos a legalizar su situación pasando por un matrimonio «ateo». 
6. Igualdad de derechos para ambos cónyuges.

7. En cuanto al apellido postmarital había tres opciones:

- Utilizar ambos cónyuges el apellido del marido.

- Utilizar ambos el de la esposa.

- Compartir un nuevo apellido.

Por lo que respecta a la adopción, ésta queda prohibida a partir de 1918, entendiendo que, de estar permitida, no haría otra cosa que reforzar el matrimonio. Pero en años sucesivos se debió hacer marcha atrás en esta medida debido a la alarmante tasa de mortalidad de los niños acogidos en centros estatales, adoptando en un principio una actitud tolerante frente a las adopciones y finalmente legitimándolas por ley en 1926.

La herencia queda abolida a partir de 1918 , si bien en sucesivas reformas, en 1922 y 1926, se volvió a legalizar aunque con un tope máximo a la cantidad a heredar que paulatinamente se fue elevando.

La legalización del aborto llega en 1920, aunque el preámbulo de la ley señala que es indeseable y únicamente producto de las circunstancias económicas y sociales.

Las numerosas reformas legales que tuvieran lugar en este corto período de tiempo no supieron anticipar los problemas que ellas mismas contribuían a agudizar: la tasa de divorcios era creciente, y tras el mismo, las mujeres siempre quedaban como responsables del mantenimiento y cuidado de los niños, mientras que la pensión alimenticia casi nunca se respetaba.

Esto, unido a la falta de servicios estatales, dejaba a la mujer en una situación dramática, puesto que debía asumir largas jornadas laborales sin que las tareas que anteriormente realizaba quedaran resueltas -trabajo doméstico, cuidado de niños-, por lo que su jornada laboral real resultaba agotadora. Además, la facilidad con que se obtenían los divorcios, dejaba a los niños sin protección, y la falta de instituciones que sustituyeran a la familia tradicional creó una atmósfera de inseguridad y desorganización, de la que era responsable sobre todo la convulsión que representó el primer plan quinquenal, que colectivizaba la agricultura y que motivó grandes movimientos de población. Se resintió particularmente la población infantil. ${ }^{5}$ Junto a estos problemas la tasa de natalidad bajó de forma alarmante, al punto que las autoridades soviéticas se vieron impelidas a preocuparse crecientemente por la familia.

5. El gobierno llegó a reconocer que no había menos de 75.000 niños abandonados en el año 1918; 125.000 en 1919 y 400.000 en 1920. En Alejandra Kollontai, La mujer..., op. cit. 


\section{EL PERIODO STALINISTA}

A partir de 1935 el Estado vuelve a intervenir en la familia, en forma de una serie de decretos cuya finalidad era fortalecerla, censurándose para ello el divorcio, el aborto y la libertad sexual. En la base de estos cambios se encontraban dos elementos en particular. Por un lado se pensaba que una familia nuevamente reforzada podía paliar las grandes tensiones de una época llena de profundos cambios, y por el otro se esperaba de la familia que ejerciera control sobre los individuos y procreara, elevando la tasa de natalidad.

No se puede olvidar que en aquellos momentos Hitler se convertía en una amenaza real en el orden exterior. $Y$ en el orden interno, la familia, y aún más la familia autoritaria, se convertía en un poderoso aliado en un país que había optado por un modelo no participativo de transición al socialismo.

Trotsky escribiría en 1938: «Guiada por su instinto de conservación la burocracia se ha alarmado por la "desintegración" de la familia.»

Reforzando la autoridad de la familia, se la hacía responsable de la conducta desordenada de los hijos. El divorcio se hizo más complicado y costoso, y el aborto se convirtió en ofensa criminal en 1936. En suma, las referencias a la familia iban en el sentido de considerarla la célula básica y el «fundamento del Estado soviético».

Finalmente, en 1944 quedó totalmente reafirmada la posición de la familia. El decreto de 1944 tenía cuatro puntos básicos:

1. Sólo se reconocían los matrimonios registrados.

2. El divorcio era más caro y únicamente se podía obtener mediante acción judicial.

3. Los niños nacidos fuera del matrimonio no tenían derecho al nombre del padre ni a sus posesiones.

La abolición del aborto legal, aunque se continuaran practicando abortos clandestinos, contribuyó a que fueran muchos los niños que se encontraran en situación de hijos ilegítimos, categoría que anteriormente únicamente se consideraba propia de la moral burguesa.

La revalorización de la institución matrimonial iba unida a una nueva actitud hacia la sexualidad. Inicialmente no se mencionaba el incesto en el Código Criminal, dado que la ciencia médica no había hallado ninguna evidencia de que causara daños psíquicos, y la homosexualidad no se consideraba un delito. Se entendía que el adulterio era un asunto privado y la represión a los polígamos tenía lugar porque era justamente en las socieda- 
des de corte más tradicional (musulmanas) de Asia Central donde la poligamia estaba presente. La desviación sexual se definía en función de la existencia de explotación sexual.

Ahora todas estas conductas quedaban proscritas -la homosexualidad en 1934- y «Pravda» atacaba el amor libre por considerarlo burgués y totalmente alejado de los principios socialistas.

Así, la familia se convertía en un medio en manos del Estado para elevar la tasa de natalidad y controlar la conducta de los individuos. Si inmediatamente después de la revolución había supuesto un obstáculo para el cambio social por sus actitudes conservadoras, por los mismos motivos la institución familiar se hacía ahora necesaria, al transmitir valores como la sumisión. Si se la reforzaba era porque ya no se temía que inculcara valores que entraran en conflicto con la política del momento, y porque el Estado era incapaz de asumir la satisfacción de todas aquellas necesidades, como preparación de alimentos, cuidado y socialización de los niños, que tradi. cionalmente correspondían al núcleo familiar.

\section{CARACTERISTICAS DE LA FAMILIA MODERNA EN LOS PAISES DEL ESTE}

Tras la segunda guerra mundial, la modalidad de surgimiento de los nuevos países socialistas - resultado en buena parte del reparto de esferas de influencia entre los vencedores, los EE.UU. y la URSS- determina que los principios que informan a la familia en estos países estén marcados por la influencia soviética.

En la actualidad, la familia en los países del Este, en particular en las zonas urbanas tiene una estructura muy similar a la de cualquier país occidental industrializado. Es una familia nuclear, con residencia neolocal (cuando las dificultades para encontrar vivienda no lo impiden).

A partir de 1968, los puntos básicos en que se fundamenta el matrimonio en estos países se acercan a la legislación liberal de los países occidentales, si bien, con respecto al divorcio, en la mayoría de países del Este es de procedimiento sumamente sencillo cuando existe el mutuo acuerdo y no hay hijos menores, cuando uno de los esposos ha desaparecido, y cuando existen desequilibrios mentales graves o uno de los consortes esté condenado a penas de prisión superiores a los tres años.

Únicamente se consideran legales los matrimonios registrados. No se establecen distinciones entre hijos legítimos e ilegítimos. $Y$ se confieren iguales derechos a ambos cónyuges. El criterio para determinar quién es el. 
cabeza de familia se establece en función de la aportación de medios para la subsistencia de la familia, y en el caso de que ambos cónyuges hagan una aportación equivalente es considerado cabeza de familia aquel o aquella que además los administre.

\section{LA INTERVENCION DEL ESTADO EN EL AMBITO DE LA PRODUCCION Y REPRODUCCION DE LA FUERZA DE TRABAJO}

En los países industrializados, incluidos los llamados socialistas, una de las dimensiones del ser humano que tiene mayor importancia para los poderes públicos es la de la producción; la intervención del Estado en la vida cotidiana ${ }^{6}$ se hace, por tanto, desde la perspectiva de producción y reproducción de la fuerza de trabajo. Reproducción de la fuerza de trabajo como actividad por la que se recuperan las energías consumidas en el proceso productivo, mediante el descanso, la alimentación, la higiene personal y la satisfacción de las necesidades emocionales y sexuales. Producción de fuerza de trabajo, entendida como todo el proceso que va desde el embarazo y la lactancia y continúa con el cuidado y socialización de los niños hasta que llegan a la edad en que se les considera en edad productiva.

Hablar de la intervención del Estado en este terreno equivale a plantearse qué papel juega, cuándo lo juega, en cuestiones tales como: sexualidad y reproducción, cuidado de los niños, consumo de las unidades domésticas, etc. $Y$ teniendo en cuenta que todas estas actividades han estado asumidas tradicionalmente por la mujer en el marco de la unidad familiar, no se puede eludir como actores de este drama a la mujer y el varón, y el nivel de diferenciación de sus roles familiares.

\section{Sexualidad y reproducción}

En la mayoría de los países del Este todavía no funcionan programas eficaces de planificación de la maternidad, pero la actitud estatal hacia estos programas varía de país a país, ya que puede decirse que en Polonia, Hungría y Checoslovaquia forman parte de la política gubernamental.

Junto a la escasez de servicios en este terreno, nos encontramos con

6. Entiendo por vida cotidiana las relaciones sociales en que el individuo actúa como un todo, el lugar de la no especialización, justamente es éste el sentido en que los situacionistas entienden lo cotidiano. 
que la legalización del aborto está generalizada, de tal modo que la ausencia de información sobre métodos contraceptivos conduce a la utilización del aborto como el medio contraceptivo más extendido.

En Polonia, por ejemplo, no se dispuso de diafragmas y anovulatorios hasta 1960 y sólo un uno por ciento de las primíparas entre 15 y 49 años había utilizado la píldora previamente a su primer embarazo. Se estima que la mitad de las mujeres casadas utiliza algún método contraceptivo, y de éstas la mitad aproximadamente dependen del coitus interruptus y del método del ritmo, lo que significa que al menos tres de cada cuatro mujeres utilizan métodos anticonceptivos ineficaces. ${ }^{7}$

En Checoslovaquia no se introdujeron los contraceptivos otales hasta 1965, y debido a los efectos secundarios de la píldora ( ¿y también a un intento disuasorio de su utilización?) se requería la prescripción del médico y someterse a seis revisiones anuales, además de que el fármaco no era gratuito.

No obstante, la tasa de natalidad en estos países permanece en los niveles de los países occidentales: según el censo soviético de 1970, que cubre también a las familias más tradicionales musulmanas, el número medio de hijos por familia es sólo de 1,5 ?

Tanto las altas tasas de aborto ${ }^{10}$ como las bajas tasas de natalidad pueden considerarse resultantes del proceso de modernización, ya que en cada uno de estos países existe una marcada diferencia entre la natalidad en medios urbanos $\mathrm{y}$ en medios rurales. $\mathrm{Y}$ como en cualquier otro país, juega también un papel importante el nivel cultural de la madre en la limitación del número de hijos. Sin embargo, y teniendo en cuenta que estamos hablando de países donde la intervención del Estado es prácticamente ilimitada - dentro de los límites que impongan los recursos económicos- puede decirse que en el terreno de la política de educación sexual y planificación de la natalidad, tiene todavía mucho camino que recorrer hasta situarse al nivel del Welfare State de los países occidentales.

7. Magdalena Sokolowska, Poland: «Women's experience under socialism», en J. Zollinger Giele y Audrey Chapman Smock, Women roles E status in eight countries, Nueva York, John Wiley \& Sons, 1977.

8. Barbara Wolfe Jancar, Women under comunism, Baltimore, The John Hopkins University Press, 1978.

9. «Wolfe, Women...», op. cit.

10. Se estima, ya que no se dispone de datos agregados, que la tasa de abortos en la URSS para 1973 giraba en torno al $150 \%$ de los nacidos vivos. Y en Hungría tenían lugar 52,1 abortos por cada cien embarazos. Wolfe, Women..., op. cit. 


\section{Los roles familiares}

La familia continúa estando ordenada jerárquicamente y aunque los criterios seguidos para determinar quién debe ser considerado cabeza de familia no tengan una base sexista, es el padre quien continúa considerándose cabeza de familia por razones de tipo económico, y según la consideración de la propia población. En Hungría, cuando recientemente se investigó entre la población cuál era el apellido que se consideraba debía utilizar la familia, una abrumadora mayoría de mujeres era favorable a que se utilizara el apellido del varón. ${ }^{11} \mathrm{Y}$ en una investigación realizada en Leningrado se observó que el $69 \%$ de las respondientes reconocían como cabeza de familia al marido. Si a esto añadimos que a efectos de censo es cabeza de familia la persona que aporta mayores ingresos, y tenemos en cuenta que por término medio los salarios de las mujeres son inferiores en un $30 \%$ a los de los varones, es fácil ver dos cosas: en primer lugar, que la familia tiene una estructura jerárquica al aparecer la figura del cabeza de familia; en segundo lugar, el varón ocupa la cima de la pirámide.

En cuanto a los roles de los cónyuges, se observan dos fenómenos interesantes: 1) La familia va quedando progresivamente vacía de contenido, en especial en lo que se refiere a la socialización de los niños y las niñas (debido fundamentalmente a la acción del Estado), ya que los servicios en este terreno están más desarrollados que en los países occidentales, si bien queda un largo camino por recorrer, como veremos más adelante, dado que las guarderías y centros preescolares están lejos de cubrir las necesidades de la población. 2) El papel del marido no se ha modificado sustancialmente, pero sí el de la mujer, ya que hoy casi todas las mujeres adultas están integradas en la producción social, aunque continúan asumiendo el papel de amas de casa.

En una investigación realizada en Yugoslavia ${ }^{12}$ en 1976, ia participación de la mujer en el trabajo doméstico muestra el cuadro (ver página siguiente).

En este cuadro podemos observar que las actividades consideradas tradicionalmente femeninas son realizadas exclusivamente por las mujeres en más de la mitad de los casos, lo cual no significa que en el resto de casos sean realizadas únicamente por el hombre, sino que pueden haber sido realizadas conjuntamente, o puede haber intervenido otra persona (la abue-

11. Información proporcionada por una periodista española residente en Hungría.

12. Ule, Meznaric y Ferligoj, Division of everyday family roles between that which is desired (society) and reality (family), ponencia presentada al Noveno Congreso Mundial de Sociología, Uppsala, 1978. 


\begin{tabular}{|c|c|}
\hline Actividad & $\begin{array}{l}\text { Sólo la mujer } \\
\text { (en porcentaje) }\end{array}$ \\
\hline Limpieza de la casa & 66 \\
\hline Planchado y lavado. & 87 \\
\hline Cocinar ................. & 66 \\
\hline Compra diaria de alimentos .................... & 47 \\
\hline Cuidado de niños enfermos .................... & 55 \\
\hline Resolver asuntos fuera de casa $\ldots . . . \ldots \ldots \ldots \ldots$ & 20 \\
\hline Decisiones de dinero $. . . . . . . . . \ldots \ldots \ldots \ldots \ldots . . . . . .$. & 22 \\
\hline Jugar con los niños .......................... & 23 \\
\hline Ayudar en los estudios a los niños ............ & 35 \\
\hline Responsabilidad en la disciplina de los niños. & 17 \\
\hline
\end{tabular}

la). A través de esta investigación se pudo observar que las funciones tradicionales están más marcadas en las familias religiosas y que en el grupo familiar con más alto nivel de vida y de educación se observa una disposición más favorable al cambio de situación. No obstante, los roles en la familia no han cambiado para el marido y para los niños, pero sí para la mujer, ya que abarca nuevas funciones que anteriormente no realizaba.

En Bulgaria, la distribución del trabajo doméstico para el año 1967 era la siguiente: ${ }^{13}$

Número medio de horas diarias empleadas en el trabajo doméstico

\begin{tabular}{|c|c|c|}
\hline & Mujeres & Hombres \\
\hline Preparación de alimentos & $1 \mathrm{~h} .33 \mathrm{~min}$. & $8 \mathrm{~min}$. \\
\hline Lavado y planchado ........................ & $40 \gg$ & $3 \gg$ \\
\hline Limpieza de la casa ........................ & 1 h. $24 »$ & $56 »$ \\
\hline Compra & $41 \gg$ & $28 \gg$ \\
\hline Cuidado de animales o huerto ............. & $30 »$ & $53 »$ \\
\hline Jugar con los niños ...................... & $31 »$ & $10 »$ \\
\hline Total horas por día. & 5 h. 19 min. & $2 \mathrm{~h} .10 \mathrm{~min}$. \\
\hline
\end{tabular}

13. «Wolfe, Women...», op. cit. 
En la Unión Soviética, en la ciudad de Krasnoiarsk, a principios de los años sesenta el trabajo doméstico estaba distribuido de la siguiente forma, en los casos en que trabajaban fuera de la casa el marido y la mujer: ${ }^{14}$ $1 \mathrm{~h} .36 \mathrm{~min}$. para los varones y $3 \mathrm{~h} .48 \mathrm{~min}$. para las mujeres.

Aunque es difícil establecer comparaciones debido a que los datos no son homogéneos, es evidente la desigual distribución del trabajo doméstico entre hombres y mujeres, y el hecho de que la incorporación al trabajo asalariado representa una menor dedicación a estas tareas, con la consiguiente pérdida en la calidad de vida que este fenómeno comporta.

\section{Mujer y trabajo}

Tal como mencionábamos al principio de este artículo, la incorporación de la mujer al proceso de industrialización fue uno de los objetivos marcados por el nuevo régimen. No es exagerado decir que este elemento, junto con el modo de acumulación primitiva que tuvo lugar en la URSS, fueron los elementos diferenciales con respecto al proceso de industrialización en los países occidentales.

Esta tendencia no sólo se ha mantenido, sino que además de crecer se ha extendido a los países del área de influencia de la URSS.

Con motivo del Año Internacional de la Mujer, el CAME publicó un libro en el que se ilustra el peso de la mujer en la producción de bienes de cambio, tanto globalmente como por sectores de la economía: «Por ejemplo, más del $80 \%$ de las mujeres búlgaras, el $85 \%$ de las mujeres de la RDA y alrededor del $90 \%$ de las soviéticas, de edad apta para el trabajo, están ocupadas en la producción social o en el estudio.» ${ }^{15}$

Tal nivel de ocupación representa que las mujeres económicamente activas están expuestas a sufrir una doble carga: el trabajo llamado social y las tareas domésticas. En este problema y en la miedida en que, como ya hemos visto, los maridos participan poco en el trabajo doméstico, el Estado tiene un papel a jugar, mucho más allá del Welfare State, sustituyendo a la mujer en sus actividades tradicionales, por lo que sería más propio hablar de un Estado Maternal. Pero veamos a continuación de qué forma y en qué medida está sustituyendo el Estado a la mujer. 1977.

14. Norton T. Dodge, Women in Soviet economy, Westport, Greenwood Press,

15. CAME, La mujer en la sociedad socialista, Madrid, Akal, 1976. 


\section{El cuidado de los niños}

En las sociedades socialistas, la maternidad se continúa considerando una de las funciones principales de la mujer, por no decir la primera. Por ello, y comparado con la mayoría de países occidentales, son muy importantes las ventajas de las que disfruta la mujer trabajadora para facilitarle la maternidad.

En Bulgaria, por ejemplo, puede beneficiarse de vacaciones pagadas a nivel de salario mínimo durante 6 meses al nacer el primer hijo, 7 meses al nacer el segundo y 8 meses al nacer el tercero; y puede disponer de una excedencia no pagada hasta que el niño haya cumplido los tres años. Además, y esto es una innovación, padre y madre tienen derecho a 60 días pagados al año para cuidar a los hijos enfermos menores de 7 años. Para las mujeres que hayan dado a luz y educado a 5 hijos o más, la jubilación se adelanta a la edad de 40 a 45 años. Se establece asimismo una política de incentivos económicos para el fomento de la natalidad.

Por otra parte, el Estado va cobrando una importancia creciente en la socialización de los niños en la primera infancia, aunque continúa estando lejos de ser la primera institución socializadora. En la educación preescolar (de 3 a 6 años) sólo se dispone de plazas para el $30 \%$ de la población infantil de esa edad.

La situación en cuanto a los servicios proporcionados a las madres trabajadoras es muy similar tanto en la URSS como en los restantes países de Europa del Este. Pero en los niveles de preescolar y guarderías se observan diferencias de un país a otro: en Checoslovaquia, las plazas de preescolar cubren al $64 \%$ de la población infantil, aunque por un lado las guarderías apenas tienen cabida para un $15 \%$ de la misma. En la RDA las guarderías cubrían en 1966 el 16,8 \% de las recesidades potenciales; en la URSS el $26 \%$; en Bulgaria en 1977 las guarderías alcanzaban al $17 \%$ de las necesidades, si bien los jardines de infancia ofrecían una cobertura del $75 \%$. Para los restantes países las cifras son inferiores.

A la vista de los datos y dado que la población activa femenina no es inferior en ningún caso al $60 \%$ de la población potencial, se sobreentiende que buena parte de los hijos de madres trabajadoras reciben su atención, durante el horario laboral, fuera del ámbito de los servicios colectivos estatales. Debido a ello, la abuela sigue siendo una institución sobre la que se apoyan las familias con hijos pequeños.

$\mathrm{Y}$ de todos modos, cuando se tiene la suerte de conseguir una plaza escolar para los niños pequeños, no puede decirse que se encuentren atendidos en condiciones modélicas, debido a los bajos salarios que predominan en este sector, ya que es una rama de la actividad relativamente desatendida 
por el Estado. ${ }^{16}$ Concretamente, en el almanaque Mujer y Rusia, aparecido en la URSS a finales de 1979 , se hacía una dura condena a las condiciones sanitarias de estos centros. ${ }^{17}$

Cabe, por otra parte, analizar las razones que impelen a las mujeres a dejar a sus hijos en las instituciones preescolares y guarderías. El profesor Kharchev ha demostrado, en un estudio sobre las ciudades de Leningrado y Kostroma, que no lo hacen porque así lo prefieran, sino que la principal razón es que no pueden quedarse en casa a cuidar de ellos, y por lo tanto se desarrolla en las madres un sentimiento de culpabilidad.

La confrontación entre los servicios colectivos y la familia como socializadores de los niños ha suscitado una larga polémica en la que los médicos, psicólogos y pedagogos se han pronunciado tanto a favor como en contra de las guarderías. ${ }^{18}$ Aun habiendo en muchos casos una postura favorable hacia éstas, todavía es muy amplia la distancia que separa la guardería ideal de la guardería teal, y lo que sí se está comprobando es que los niños que acuden a estos centros padecen muchas más enfermedades que aquellos que reciben un cuidado individualizado por parte de la madre, abuela $o$ vecina.

\section{Otros servicios colectivos}

El trabajo doméstico no acaba con el cuidado de los niños, existen otras tareas en la casa que son susceptibles de ser realizadas a partir de los servicios colectivos. Los datos de que se dispone para conocer la situación de estos centros son escasos y dispersos. No obstante, se ha observado que la utilización de los mismos está altamente correlacionada con dos variables, el nivel educativo y el número de hijos (o, lo que es lo mismo, la carga del trabajo doméstico).

En general, estos servicios son escasos y poco utilizados, debido a su mala calidad, sus precios y la distancia a que se encuentran de los centros de trabajo y de la vivienda. En Checoslovaquia, sólo un $20 \%$ de los trabajadores hacen su comida principal en el comedor de la fábrica, y se ha

16. Nick Eberstadt, La crisis sanitaria en la URSS, «Teoría», núm. 7, 1981. El autor hace un análisis de las condiciones sanitarias en la URSS como medio para explicar el descenso de la esperanza de vida del ciudadano soviético, tocando, entre otros temas, el de la mortalidad infantil.

17. Collectif de redaction de l'almanach, Femmes et Russie, 1980, París, Des Femmes, 1980. (Traducción al francés del mencionado almanaque.)

18. Sobte esta polémica, ver el capítulo «Collective Vs. family care», en Hilda Scott, Does socialism liberates women?, Boston, Beacon Press, 1975. 
estimado para 1980 que la ropa se lavó sólo en un $10 \%$ en las lavanderías, donde se producen retrasos de quince días en la entrega de la ropa limpia, a menos que se opte por el servicio «express», que no lo es tanto, ya que entonces la entrega tiene lugar al cabo de cinco días y el precio sufre un recargo del $30 \%$.

\section{El aborro de trabajo con electrodomésticos}

Si las mujeres deciden prescindir de los servicios colectivos o no tienen más remedio que prescindir de ellos, dados sus precios y escasez, parece que una solución para aliviar la carga del trabajo doméstico sería disponer de electrodomésticos; no obstante, también en este terreno la situación dista de ser satisfactoria.

Según el censo de la Unión Soviética de 1970, una de cada dos familias disponan de televisor y lavadora, y una de cada tres disponían de frigorífico (precisamente en un país donde la compra de alimentos perecederos supone grandes pérdidas de tiempo). Pero los estudios de Kharckev muestran cifras mucho más bajas. Además, resulta llamativo que se disponga de más televisores que frigoríficos, y en absoluto se puede argumentar que la gente así lo prefiere, ya que sabemos que la demanda de productos no es autónoma, y menos en un país con planificación central, como es la URSS. Podemos entender, por tanto, que puede deberse a una política estatal el hecho de que se disponga de más televisores que de frigoríficos, que explicita por una parte una falta de valoración del trabajo doméstico y la sobrecarga que éste supone para las mujeres que además trabajan fuera de casa, mientras que la televisión puede resultar sumamente útil como medio de transmisión de ideología.

En Hungría, en 1972, por cada 100 familias había 67 lavadoras, 46 frigoríficos y 37 aspiradoras, en comparación con 1960, en que había 51, 1 y 4 respectivamente. En Bulgaria tienen lavadora el $50 \%$ de las familias y casi el $60 \%$ disponen de refrigerador.

Para Checoslovaquia las cifras son de $83 \%$ y $75 \%$.

Como conclusión, aunque no puede decirse en absoluto que exista un total desabastecimiento de electrodomésticos en estos países, éstos no llegan a cubrir las necesidades de la población. Agravante de esta situación es el hecho de que no menos del $80 \%$ de las mujeres adultas trabaja fuera de casa, por lo que la insuficiencia de los servicios colectivos y electrodomésticos repercute en unas condiciones de vida durísimas y en jornadas de trabajo que se alargan, restando tiempo al ocio y al sueño. 


\section{La compra diaria}

La compra de alimentos es una tarea que debe realizarse diariamente debido a que los frigoríficos y los congeladores distan mucho de estar generalizados, y todavía es la mujer la que suele realizarla en su mayor parte. Si tenemos en cuenta que en las grandes ciudades desplazarse de casa al trabajo representa una hora de viaje, y que la mujer es la que lleva y recoge a los niños de la escuela, se comprende mejor la sobrecarga que supone para ella la compra diaria. Aunque en todos estos países el sistema de compra es parecido al occidental, es difícil planificarla, ya que los abastecimientos deficientes hacen que continuamente escaseen o falten algunos productos de consumo diario. En la URSS, además, es necesario hacer una cola para seleccionar la compra, otra para pagar y una tercera para recogerla. Esto supone, además, una inversión mayor de esfuerzo imaginativo y de tiempo en la cocina, para producir platos según lo que en aquel momento haya en el mercado.

\section{La vivienda}

La escasez de vivienda es uno de los grandes problemas, en especial en la Unión Soviética, donde todavía es frecuente que el joven matrimonio viva con sus padres durante los primeros años por dificultades para encontrat vivienda independiente. Esto comporta sus ventajas y sus inconvenientes, las tareas domésticas quedan más repartidas dado que hay dos mujeres en la casa, pero por otra parte es una fuente de conflictos familiares, ya que las viviendas acostumbran a ser de tamaño reducido.

En la URSS, desde hace diez años, se ha empezado a trasladar a las familias de los apartamentos comunales, ${ }^{19}$ en los que tenían que compartir la cocina y el baño con otras familias, a apartamentos unifamiliares. En el almanaque Mujer y Rusia se hace también referencia a este problema, destacando las enormes incomodidades que causan, en particular a las mujeres, estas condiciones de vida, ya que compartir cocina y baño no ha llevado a compartir las tareas domésticas, y el ama de casa ha de esperar su turno para hacer la comida, lavar la ropa o bañar a los niños. Se cal-

19. Es difícil creer que la creación de los apartamentos comunales obedeciera exclusivamente a un intento de desarrollar nuevas formas de vida, tal como lo plantea A. Kollontai en La bolchevique enamorada (libro editado en castellano por La Sal, Edicions de les Dones), sino que, por el contrario, el númeto de viviendas urbanas resultó insuficiente en los primeros años de la revolución, debido a los grandes traslados de población del campo a la ciudad, motivados por la industrialización del país. 
cula que más de la mitad de la población vive todavía en estas condiciones.

La vivienda es uno de los problemas más graves a que se enfrentan estos países. Durante el período de desarrollo económico intensivo se dio prioridad a la industria pesada, sólo a partir de 1950 se pasó a considerar como prioritaria la vivienda. Además, la rápida tasa de urbanización no ha hecho sino empeorar el problema; según el censo soviético, tres de cada cuatro personas que viven en las ciudades son emigrantes del campo.

La alta participación de la mujer en la población activa hace que la escasez de servicios colectivos unida a su ineficacia, las dificultades para abastecer a la familia y la insuficiencia de viviendas, sean problemas que adquieren una particular dimensión en estas sociedades. Ya hemos visto la deficiente solución que se ha dado a cada uno de ellos por parte del Estado, también hemos visto cómo la mujer queda aprisionada entre estas dos instituciones: el Estado y la familia, y cómo a causa de las deficiencias del Estado y de la división tradicional de funciones en la familia, se ve obligada a acarrear una pesada carga, de la que se resienten necesariamente las relaciones familiares y sociales.

Esta situación de la mujer queda ilustrada con particular viveza en un reportaje sobre la vida de una mujer polaca ${ }^{20}$ en el que se explica que tomando el turno de noche puede llegar a casa para arreglar a los niños para ir a la escuela, y hacer las compras diarias; y tras un corto sueño hacerse cargo del trabajo de la casa, mientras el marido, durante el día está trabajando. ¿Dónde está presente la intervención del Estado para resolver estos problemas?

\section{CONCLUSIONES}

Hasta aquí hemos visto cómo el modelo soviético, que después se implantaría en las sociedades de su área de influencia, enfatiza particularmente los aspectos de explotación del individuo que están presentes en el modelo alternativo (el capitalista), de tal modo que se produce un cierto reduccionismo manifiesto en la centralidad que, para el cambio revolucionario, tiene la eliminación de la propiedad privada.

Paralelamente a la desprivatización de los medios productivos se pone en marcha un proceso de industrialización frenado hasta la fecha por la persistencia de estructuras feudales. La industrialización, cuya superioridad en términos de eficiencia en el terreno económico no es necesario

20. A day in the life of a Polish woman, «Spare Rib», núm. 109, 1981. 
señalar, tiene efectos socio-políticos también positivos para el nuevo Estado, puesto que amplía la base social del régimen absorbiendo buena parte del campesinado y de las mujeres, sectores sociales que de otro modo podían oponer una resistencia considerable al régimen soviético.

Otra fuente de resistencia al nuevo Estado la constituye la institución familiar. Los ideólogos del Partido Bolchevique entienden que la familia es un estorbo y un peligro, por considerar que era transmisora de valores burgueses. Se impone la necesidad de debilitarla al máximo, ocupando el espacio que deja vacante el Estado. De cualquier modo, e independientemente de consideraciones de carácter superestructural, la incorporación masiva de la mujer a la producción ${ }^{21}$ impone la necesidad de crear servicios colectivos, sustitutivos de su trabajo doméstico, so pena de un descenso alarmante en la calidad de vida de la población.

Son dos las críticas fundamentales que se le pueden hacer al modelo soviético. Empecemos por su funcionamiento. Es un modelo que se caracteriza por la incorporación masiva a la división técnica del trabajo de las personas en edad de trabajar. A menos que se produzca una sobreexplotación de las personas ocupadas previamente en las actividades relacionadas directamente con la producción y reproducción de la fuetza de trabajo (nos estamos refiriendo sobre todo a las mujeres) o que el Estado se haga cargo de estas tareas, el modelo se pone en crisis por sí mismo.

La solución aportada en los países de socialismo real que estamos comentando pasa por un camino intermedio entre la estatalización de los servicios mencionados: con la creación, por una parte, de servicios relacionados con la producción y reproducción de la fuerza de trabajo (comedores colectivos, guarderías hospitales, lavanderías, etc.) y por otra, la provisión de estas necesidades en la unidad familiar, aumentando la productividad del trabajo del ama de casa (que a la vez es trabajadora asalariada) mediante la producción de electrodomésticos. No obstante, y tal como hemos visto en las páginas precedentes, los servicios colectivos de que se dispone en estos países no llegan a cubrir las necesidades reales, por una insuficiencia de doble carácter. Cuantitativamente hablando, no hay suficientes cantinas, ni guarderías, ni hospitales, ni asilos, ni lavanderías, por lo que buena parte de estas necesidades deben cubrirse necesariamente en forma no colectivizada. Y desde el punto de vista cualitativo, estos servicios son de baja calidad; un indicio de ello, sin entrar en mayores detalles, son los bajos salarios que se pagan en el sector.

Por la vía de incrementar la productividad del trabajo doméstico, los

21. Sobre la incorporación de la mujer a la producción es interesante el artículo de Hilda Lass, ¿La solución final a la cuestión femenina?, «Papers», núm. 9, 1978. 
electrodomésticos continúan sin cubrir las necesidades de la población, y además, buena parte del trabajo que se realiza en la casa no es susceptible de mecanización. La solución individualizada entra en contradicción con la ideología socialista «oficial».

Se nos ocurre que los descensos en la tasa de natalidad que tanto alarman a los gobernantes de estos países, pueden muy bien estar relacionados con esta situación. Es difícil persuadir a una mujer de que tenga más hijos, cuando es consciente de que no van a estar correctamente atendidos, a menos que esté dispuesta a pagar el precio de su salud, prolongando su jornada laboral a costa de restar horas al sueño.

Ahora bien, y aun cuando es pertinente analizar los problemas de funcionamiento del modelo soviético, la crítica fundamental reside en su propio planteamiento. Un intento de salarizar todo el trabajo socialmente necesario plantea graves objeciones. Tal modelo conduce a una sociedad basada en relaciones funcionales, por ejemplo: relaciones entre paciente y enfermo, entre alumno y profesor, entre conductor de autobús y usuario; sin potenciar, e incluso frenando, las relaciones entre prójimos (relaciones entre personas que se reconocen en tanto son miembros de la comunidad humana) en que el individuo es tomado en toda su dimensión. Y esto, en definitiva, debido a que el intento del Estado de sustituir todo el trabajo que realiza la mujer supone que para resolver las necesidades más inmediatamente relacionadas con la supervivencia humana, se salarice el trabajo que hasta entonces había sido gratuito, y con esta salarización se refuerzan las relaciones funcionales.

El trabajo pasa a convertirse, bajo tales circunstancias, en algo fuera de la esfera de la decisión individual, impuesto desde el exterior y separado de los sentimientos. En estas condiciones, la persona difícilmente puede integrarse en el colectivo social, porque el referente que debiera motivarle se encuentra demasiado apartado. Trabaja para unos iguales, unos viejos, unos niños, unos enfermos que no puede sentir en sí mismo, dado que él, sus viejos, sus niños y sus enfermos han dejado de ser su problema y han pasado a ser responsabilidad de la sociedad, el problema de la sociedad. Este sentimiento de alienación es el caldo de cultivo para el «absentismo social», porque la sociedad se convierte en algo alejado y carente de significación.

Subyace a la salarización del trabajo doméstico, mediante la creación de servicios colectivos, un intento de integrar a la mujer en el mundo del varón y no una síntesis de los dos mundos. Este planteamiento supone una aproximación androcéntrica a la problemática de la mujer y de la familia. El Estado ha intentado suplantar a la mujer en el trabajo que tradicionalmente venía realizando. Éste es un intento de que todas las necesidades 
materiales se resuelvan en la esfera de los bienes de cambio, con la intervención del trabajo asalariado, vaciando así de contenido el reducto más importante que quedaba para el trabajo autónomo: ${ }^{22}$ la familia.

$\mathrm{Y}$ aún más, con todo esto, lo que se consigue es que nadie escape a una actividad que no controla ni en cuanto a calidad ni en cuanto al tiempo que se le destina. Si inicialmente sólo la mujer era considerada una menor de edad, con esta nueva situación lo son realmente todos los miembros de la sociedad, el Estado PATRón proporciona trabajo, el Estado PADRE proporciona seguridad y medios de vida, y el Estado MADRE pretende producir los cuidados de que antes eran responsables las mujeres.

¿Dónde queda espacio para la libre determinación de cómo y en qué condiciones se relacionan los individuos?

¿Existe una alternativa posible? $Y$ en particular, ¿existe una alternativa a la familia? La alternativa pasa por delimitar al máximo los poderes del Estado liberando espacios para la autonomía individual, lo que no tiene por qué significar el aislamiento y la insolidaridad, sino que por el contrario, supone sentar las bases para superar la separación que en las sociedades modernas se produce entre edades y sexos.

22. André Gorz, Adiós al proletariado, Barcelona, «El Viejo Topo», 1981. Gorz utiliza el têrmino trabajo autónomo contraponiéndolo al trabajo heterónomo que coincide con el trabajo asalariado. 